\title{
Introducing Reviews in Colorado Archaeology, a New Online Journal for Archaeological Research and Cultural Resources Management
}

\author{
MARK D. Mitchell \\ Research Director, Paleocultural Research Group
}

\begin{abstract}
Decisions about which sites to preserve and study are among the most critical that archaeologists make. Sound preservation decisions depend on well-supported assessments of archaeological site importance, which in turn depend on agreed frames of reference or contexts. For archaeologists working in Colorado and adjacent regions, one of the most important frames of reference is a series of context documents published by the Colorado Council of Professional Archaeologists. As is true of any synthesis of archaeological data, those contexts are now in need of renewal, and in some cases revision. To provide one venue for context updates, Paleocultural Research Group has inaugurated an online, refereed journal called Reviews in Colorado Archaeology (RCA) that publishes authoritative and critical reviews, original research, National Register contexts, and methodological primers. RCA also publishes separately numbered, book-length contributions and distributes monographs or edited volumes produced by universities, federal or state agencies, or other organizations. RCA is one component of a new website designed to support research, cultural resources management, and public education in Colorado archaeology. Called "Online Resources for Colorado Archaeology and Historic Preservation," or ORCA, the site is an open-access platform that integrates a reference library, a compendium of hyperlinks to online resources, a forum for community discussion and professional collaboration, and resources for educators, students, and avocationals.
\end{abstract}

Keywords: cultural resources management; archaeological research; historic contexts; Colorado archaeology; online journal

Productive archaeological research depends on knowing which sites to investigate, how to investigate them, and which research questions to ask. Effective cultural resource management depends on knowing which sites to preserve and how to protect and interpret them. Making good decisions about which sites to preserve and study requires a clear understanding of which sites are important. But site importance is not a self-evident or unchanging quality. Rather, the importance of a place, and the material remains of the past it contains, is a contextual judgment: it lies in the relationships we establish between the characteristics of that place and our common stock of knowledge about the past (Darvill 2005). For example, we need to know something about the temporal distribution of sites in a region to determine whether a particular site is important because it exemplifies a poorly represented period. Similarly, we can judge a cultural landscape to be representative of an important historical pattern, theme, or trend only if we know something about the broader historical context.

Fifty years after the passage of the National Historic Preservation Act (NHPA), archaeologists are accustomed to thinking about site importance 
in terms of the narrow technical meanings of the terms "significance" and "integrity." Sites are judged to be significant-and therefore worthy of investigation and preservation-if they meet at least one of the four criteria for National Register of Historic Places (NRHP) eligibility and if they retain sufficient integrity. NRHP significance evaluations clearly are contextual judgments: under the law, an archaeological site "is not eligible if it cannot be related to a particular time period or cultural group and, as a result, lacks any historic context within which to evaluate the importance of the information to be gained" (National Park Service 1997b:22; emphasis added). NRHP eligibility evaluations-and, by extension, effective cultural resources management-requires authoritative and sufficiently current context documents to "link historic properties to important historic trends" (National Park Service 1997a:4).

Of course, NRHP eligibility is not the only technical standard for site importance, either in the U.S. or elsewhere in the world (e.g. Briuer and Mathers 1997; National Park Service 2002). Individual federal agencies have developed supplementary standards, such as the Forest Service's "priority heritage asset" designation (U.S. Forest Service 2015). Most developed countries employ one or more national systems for assessing site importance (e.g. Darvill 2005). The UNESCO Convention Concerning the Protection of the World Cultural and Natural Heritage uses a distinct set of criteria to designate World Heritage sites (World Heritage Committee 2017). However, in each case, the criteria used to identify important sites are designed to establish a contextual relationship between a particular resource and a body of knowledge about the past.

Frameworks for evaluating site importance are not static. The NHPA was enacted at a time when archaeologists' research and preservation efforts commonly focused on the largest, most complex sites in a region. We now recognize that significance determinations may need to consider the broader cultural landscape, including both large and small sites as well as sites that reflect the varied ways people manifest their lives in different settings (Doelle et al. 2016). The large energy exploration and infrastructure projects of the last 50 years, as well as the cumulative effects of smaller-scale development, have shifted federal and some state resource planning to the landscape level. This emerging approach offers a complementary frame of reference for evaluating the collective importance of integrated groups of sites that can be used in conjunction with site-specific evaluations.

Site evaluations carried out under the NHPA, or under any other legal mandate, primarily have consequences for site management, whether at the level of individual sites or larger cultural landscapes. However, research archaeologists use criteria that are fundamentally similar to the NPHA standards to decide which sites to study and how to study them. We recognize that sites "acquire scientific significance when their systematic study may be expected to help resolve current research problems" (Schiffer and House 1977:249). Those research problems constitute contextual frames of reference for making decisions about which sites to investigate, just as NRHP contexts constitute frames of reference for making decisions about which sites to preserve.

However, Schiffer and House's (1977) inventory of scientific importance criteria also identifies a criterion not commonly considered in NRHP evaluations, which is a site's capacity to advance archaeological method and theory. Particular sites, or types of sites, offer unique opportunities to develop our theoretical approaches and data gathering methods. However, over the past 40 years, we also have come to recognize that the reverse is equally true: our theoretical stance and the research techniques we use can affect the decisions we make about which sites are worthy of investigation. For example, Altschul (2005) shows that the choice of theoretical framework can affect whether a site is likely to yield important information and therefore be eligible to the NRHP. Similarly, we know that the development of new methods, such as geophysical surveys, can increase the variety of archaeological sites relevant to particular archaeological problems. Moreover, we increasingly are aware that the accelerating accumulation of large datasets offers new opportunities for-and demands new approaches to-archaeological research and NHPA compliance (Schlanger et al. 2015).

Archaeologists also recognize that the educational, aesthetic, cultural, and economic values represented by historic properties are as 
important for making preservation decisions as are assessments of their research importance (Lipe 1984, 2006). Cultural heritage in the form of artifacts and historic properties embodies a past that otherwise can be difficult for people to appreciate: visiting a well-interpreted site is more compelling than simply reading about the past in a technical report. Some sites, such as traditional cultural properties, may carry special meaning for particular groups, whether or not they are evaluated as eligible for the NRHP (Darvill 1995; King 2003). Historic places also may offer local and regional economic benefits through heritage tourism. Assessments of publicly recognized cultural or economic value are not divorced from our technical assessments of NRHP eligibility or research potential; preservation decisions must make sense to a wider public if we are to sustain and increase their support for our work.

Whether they are explicit or implicit, up-todate contexts for assessing site importance and value are essential to our most important tasks. The contexts we use to decide which sites to investigate and preserve should keep pace with the continuous flow of research and management. To ensure good decision-making they have to evolve as old questions are answered, as new sites are discovered and evaluated, as new methods or conceptual frameworks are developed, and as new stakeholders make their values known. It is therefore incumbent on us to regularly renew our archaeological contexts and to think critically about the preservation and research choices we make. The need for up-to-date frames of reference should also lead us to think creatively about how best to write and disseminate documents that reflect our most recent findings.

\section{The Current Generation of Colorado Contexts}

For archaeologists working in Colorado and adjacent regions, decisions about site importance have been anchored for many years by a series of six context documents published by the Colorado Council of Professional Archaeologists (CCPA). The first five contexts, published in 1999, together summarize what was then known about the state's American Indian archaeology. They also identify gaps in the record and offer guidance on how to evaluate new discoveries and plan future research.
Now commonly called the "Colorado prehistoric contexts," each of these refereed volumes covers a region defined by one of the state's four major river basins: the Rio Grande, the South Platte River, the Arkansas River, and the Colorado River. Owing to complexity of the ancestral Pueblo record in the state's southwestern corner, the Colorado River basin is subdivided into northern and southern sections, yielding a total of five volumes. The sixth CCPA context, covering the historical archaeology of American Indians and settlers statewide during the last 500 years, was published in 2007.

Although they vary somewhat in scope, each of the five prehistoric contexts describes the regional environmental and paleoenvironmental setting, reviews the history of archaeological investigations, summarizes the known culture history, and lists critical data gaps and directions for future research. American Indian perspectives on the past and on the process of cultural resource management also are discussed to varying degrees. Several volumes include lists of radiocarbon dates, annotated bibliographies, thematic maps, or other special sections. Relatively little attention is given in any of them to specific site management issues or methodological problems.

The historical archaeology volume, with its narrative emphasis on broad themes such as "rural agriculture" or "Victorian mining settlements," more closely resembles a National Register context than do the prehistoric contexts. In addition, a variety of methodological problems are addressed and site significance and NRHP eligibility criteria for associated property types are discussed explicitly. However, little attention is given to the regional environment and its effects on human occupation or to the history of historical archaeological research.

Anecdotal evidence suggests that the six CCPA context documents are widely read and used: most are in their third printing and all are frequently cited. However, to better gauge the contexts' impact on professional practice, in 2016 Paleocultural Research Group (PCRG) used an online survey to ask CCPA members how frequently and in what ways they used the contexts. The survey was also sent to members of the Colorado Archaeological Society-who mostly are avocationals-and to university anthropology departments, museums, and other institutions in the state. 
The views of experienced practitioners are overrepresented in the poll results compared to those of the overall population of professional and avocational archaeologists working in the state (table 1). Just seven of the 208 respondents had not yet earned a Bachelor's degree, while 150 had earned either a master's degree or a doctorate. About half of the respondents had more than 20 years of experience in archaeology. Nevertheless, the results show how important the six CCPA context documents have become for the conduct of archaeological research and cultural resources management in the state.

The six context documents exhibit remarkably similar usage profiles (figure 1). For each context, about one-third of respondents reported that they had not read it, but nearly as many reported that they occasionally consult it for research or project work. Another 18 percent indicated that they consult it regularly. On average, 40 percent reported that they own a copy, while another 38 percent report that they have access through their employer or university library.

Among respondents currently employed in archaeology, fully three-quarters report that the CCPA context they use most frequently is either "very valuable" or "critical" for their work. However, the value professionals assign to the contexts varies across tasks. Figure 2 illustrates the contexts' importance for a variety of uses, organized from left to right according to the percentage of respondents who report that the contexts are critical for that particular use; the same data are given in table 2 .

Forty percent consider the contexts to be critical for preparing background sections of reports, while 27 percent consider them critical for learning about
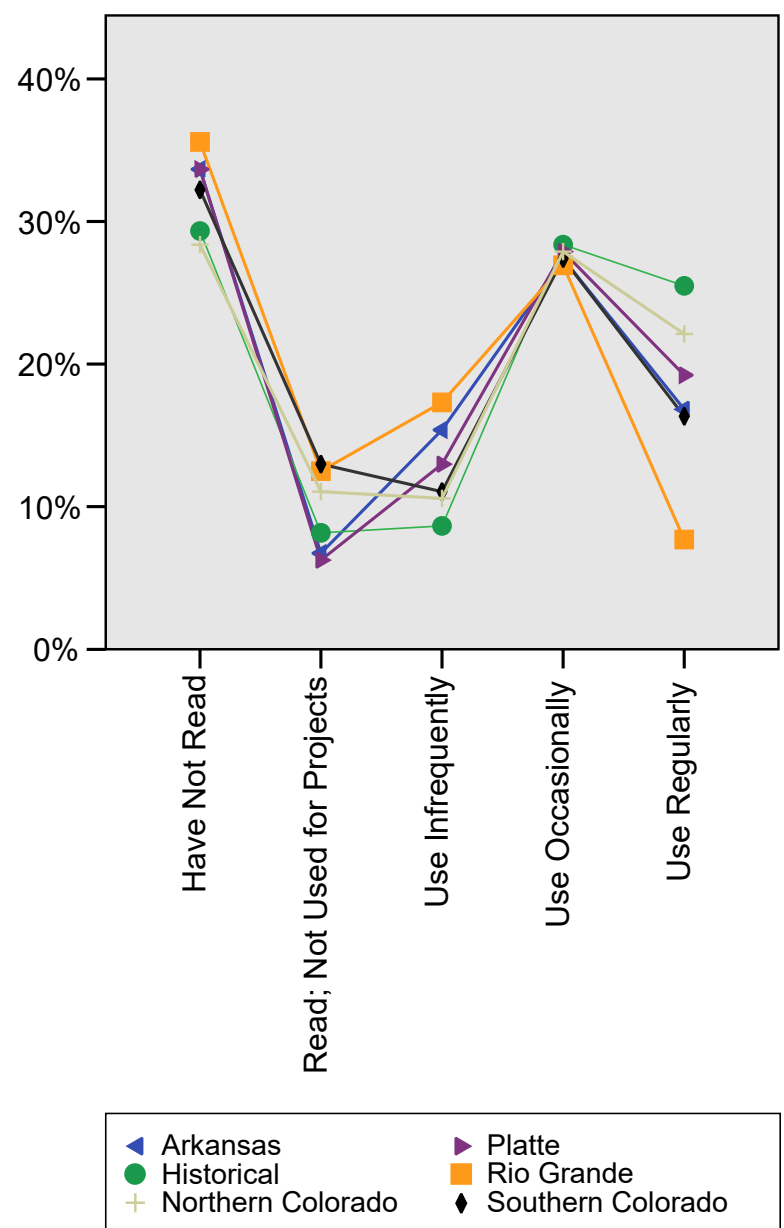

Figure 1. Usage rates for the six CCPA contexts.

an unfamiliar region or for developing research designs. The least important use is designing field methods for a project, an unsurprising result given the absence of methodological discussion in the 1999 contexts. The fact that so few respondents consider them to be critical for writing undergraduate papers

Table 1. Cross-tabulation of survey respondents' employment setting and experience.

\begin{tabular}{|c|c|c|c|c|c|c|c|}
\hline \multirow[b]{2}{*}{$\begin{array}{l}\text { Years of } \\
\text { Experience }\end{array}$} & \multicolumn{6}{|c|}{ Employment Setting } & \multirow[b]{2}{*}{ Total } \\
\hline & $\begin{array}{l}\text { Not Currently } \\
\text { Employed in } \\
\text { Archaeology }\end{array}$ & $\begin{array}{c}\text { Cultural } \\
\text { Resources } \\
\text { Management } \\
\text { Firm } \\
\end{array}$ & $\begin{array}{c}\text { Government } \\
\text { Agency }\end{array}$ & $\begin{array}{c}\text { Museum or } \\
\text { Nonprofit }\end{array}$ & $\begin{array}{l}\text { Academic } \\
\text { Institution }\end{array}$ & Other & \\
\hline $0-5$ & 7 & 1 & 2 & 1 & 3 & 2 & 16 \\
\hline $5-10$ & 8 & 10 & 7 & 2 & 6 & & 33 \\
\hline $10-20$ & 9 & 22 & 14 & 4 & 2 & 1 & 52 \\
\hline More than 20 & 14 & 44 & 23 & 10 & 13 & 3 & 107 \\
\hline Total & 38 & 77 & 46 & 17 & 24 & 6 & 208 \\
\hline
\end{tabular}




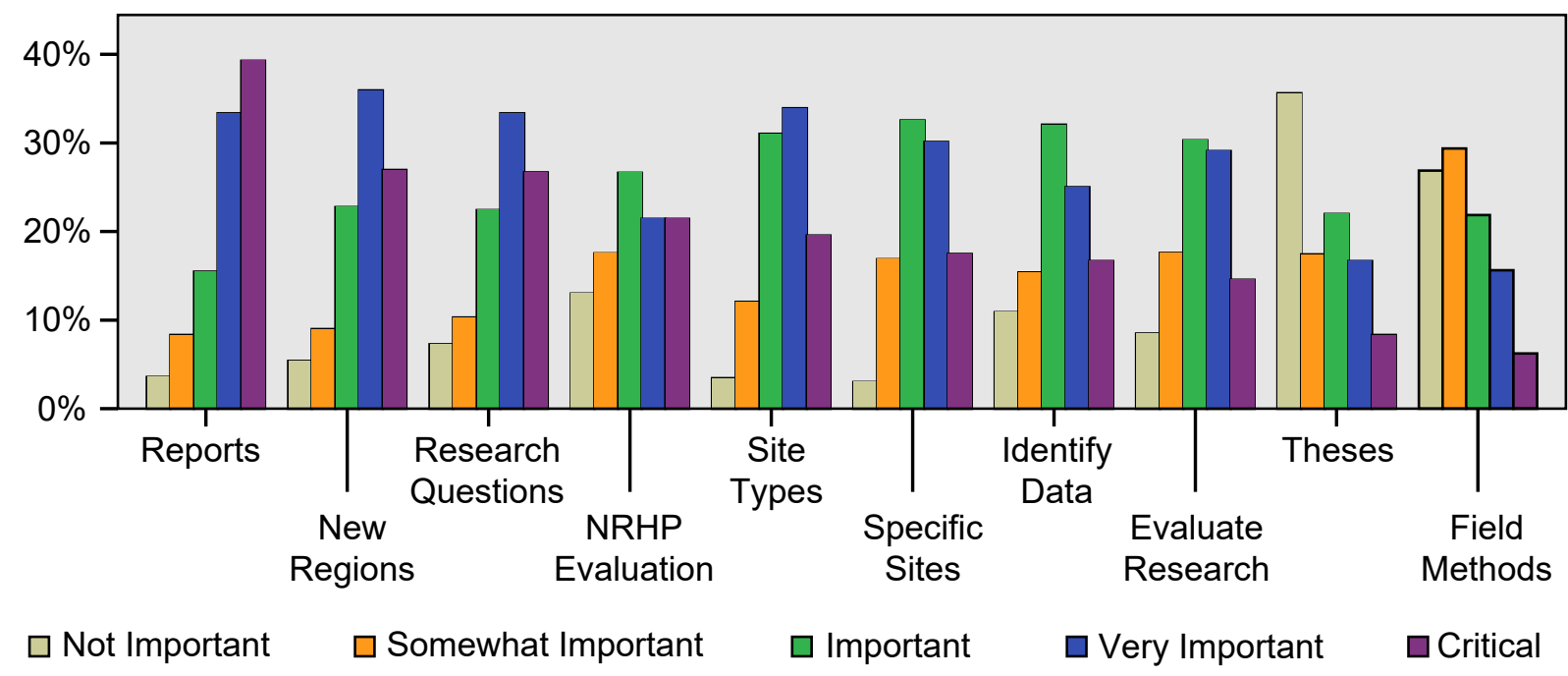

Figure 2. Survey respondents' assessments of the importance of the CCPA context documents for a range of activities.

and graduate theses no doubt reflects the fact that the vast majority of respondents are older and more experienced, rather than their actual utility for those tasks.

These data confirm what many archaeologists working in Colorado already know from personal experience: the CCPA contexts are now integral to their work. Many routinely use them to prepare reports, learn about new regions, develop research designs, and evaluate sites. But perhaps precisely because they are so valuable, Colorado archaeologists also recognize that the prehistoric contexts need to be brought up to date. More than 18 years have passed since they were published, whereas just 15 years passed between the publication of the CCPA contexts and the publication of the documents they were designed to replace, the Colorado Historical Society's Resource Protection Planning Process (RP-3) volumes. While the current contexts are and will remain valuable tools, the rapid pace of archaeological documentation and research in the state is making them increasingly outdated.

The nature and extent of needed updates varies among the five prehistoric contexts. For the southern Colorado River basin context area, a surge of innovative academic research and NHPA

Table 2. Survey respondents' assessments of the importance of the CCPA context documents for a range of professional activities, ranked according to the proportion of respondents who rated them "critical."

\begin{tabular}{lcccccc} 
& & \multicolumn{4}{c}{ Importance Score } \\
\cline { 3 - 6 } Function & Rank & $\begin{array}{c}\text { Not } \\
\text { Important }\end{array}$ & $\begin{array}{c}\text { Somewhat } \\
\text { Important }\end{array}$ & $\begin{array}{c}\text { Very } \\
\text { Important } \\
\text { Important }\end{array}$ & Critical \\
\hline Prepare Reports & 1 & $3.6 \%$ & $8.3 \%$ & $15.5 \%$ & $33.3 \%$ & $39.3 \%$ \\
Learn About a New Region & 2 & $5.4 \%$ & $9.0 \%$ & $22.8 \%$ & $35.9 \%$ & $26.9 \%$ \\
Develop Research Designs & 3 & $7.3 \%$ & $10.3 \%$ & $22.4 \%$ & $33.3 \%$ & $26.7 \%$ \\
Make NRHP Evaluations & 4 & $13.0 \%$ & $17.5 \%$ & $26.6 \%$ & $21.4 \%$ & $21.4 \%$ \\
Learn About an Artifact or Site Type & 5 & $3.4 \%$ & $12.1 \%$ & $31.0 \%$ & $33.9 \%$ & $19.5 \%$ \\
Learn About Specific Sites & 6 & $3.0 \%$ & $16.9 \%$ & $32.5 \%$ & $30.1 \%$ & $17.5 \%$ \\
Identify Datasets & 7 & $10.9 \%$ & $15.4 \%$ & $32.1 \%$ & $25.0 \%$ & $16.7 \%$ \\
Evaluate Research Outcomes & 8 & $8.5 \%$ & $17.6 \%$ & $30.3 \%$ & $29.1 \%$ & $14.5 \%$ \\
Write Papers or Theses & 9 & $35.6 \%$ & $17.4 \%$ & $22.0 \%$ & $16.7 \%$ & $8.3 \%$ \\
Design Field Methods & 10 & $26.9 \%$ & $29.4 \%$ & $21.9 \%$ & $15.6 \%$ & $6.3 \%$ \\
Total & & $11.1 \%$ & $15.2 \%$ & $25.8 \%$ & $27.8 \%$ & $20.0 \%$ \\
\hline
\end{tabular}


compliance projects has greatly expanded what is known about ancestral Pueblo history. In the Rio Grande basin, more than 15,000 acres have been inventoried since 1999. Numerous large-scale excavation projects have been carried out in the northern Colorado River context area over the past 20 years, permitting for the first time a detailed understanding of regional settlement systems. The growth of cities on Colorado's Front Range has prompted major projects in the South Platte River basin, adding significantly to the regional database.

In addition, critical advances have occurred on topics that the contexts cover only minimally, or not at all. Rock art is an important aspect of the state's archaeological record but is only briefly discussed, and then primarily in descriptive terms. American Indian consultation is discussed but native knowledge about the regional archaeological record, including the rock art record, is not systematically examined. Research on aboriginal wooden features, culturally modified trees, basin houses, and other topics only briefly discussed in the 1999 contexts has expanded tremendously in the past two decades.

Many of the reports describing work carried out since 1999 are distributed only in limited quantities. As a result, much of the data accumulated during the last two decades have yet to be integrated with the existing CCPA contexts. Researchers and consulting archaeologists may therefore lack the most up-todate data and interpretations when making NRHP eligibility recommendations or when designing and executing survey and mitigation projects. Federal and state archaeologists may similarly be deprived of the most up-to-date findings when they evaluate the results of compliance projects or when they design long-term preservation programs.

\section{The Next Generation of Colorado Contexts}

No one now doubts the value of the internet for disseminating information and it is unavoidable that internet-mediated publishing will feature prominently in any updates to the existing Colorado contexts. The internet offers greater access, greater timeliness, and greater flexibility, all at lower cost. Digital data distribution also offers us with features that print publishing simply cannot provide, including access to large datasets, search functionality, 3D visualization, rapid scalability, and more. But the online environment also challenges aspects of scholarly publishing that remain crucial for the practice of professional archaeology.

Like that of any scientific discipline, archaeological knowledge is the cumulative product of a community composed of individuals with unique experiences and perspectives. Progress in scientific research also requires a stable framework built from agreed upon theories, models, and analytic methods. Traditional scholarly publishing, incorporating peer-review, copyright protection, and stable, citable media, has filled those needs in the past. One of the main concerns raised in early discussions of online formats was that they would not similarly safeguard the quality and stability of the research product.

Fortunately, a variety of internet-mediated publishing models now exist that simultaneously maximize the advantages of the new digital environment while preserving the bedrock features of scholarly publishing. With their lower production and distribution costs and shorter turnaround times, online books and journals can better keep pace with the continuous, but uneven, nature of archaeological research and documentation and at the same time provide a stable product that the community can reference, use, and critique. Online books and journals can also be linked to tabular or spatial datasets, images, and other media, expanding options for disseminating information and increasing opportunities for collaboration.

For authors, digital publishing offers a chance to more quickly disseminate research that reflects their specific expertise, while at the same time ensuring that they receive the recognition they deserve. Increased flexibility in scope and content can also democratize the process of context development, by increasing the number and variety of authors. For readers, digital publishing can increase access to the most up-to-date interpretations, while at the same time providing assurance that the product reflects the community's scholarly standards.

If the advent of internet-mediated publishingcombining the speed and accessibility of online distribution with the stability of traditional peerreviewed publishing-promises new avenues for updating the Colorado contexts, it also likely signals the waning of the model used so successfully 
to produce the first two generations of context documents. Writing comprehensive volumes primarily for print distribution is simply too expensive and too time consuming. And high costs and complex production schedules lead to intervals between revisions that are too long. Internetmediated publishing, by contrast, encourages a trade-off between scope and speed: in the new medium, updates may be less comprehensive but will be timelier. Updates will also be more numerous and a larger proportion of the scientific community will contribute. PCRG's new online journal, Reviews in Colorado Archaeology, is one such internet-mediated venue for archaeological context development.

\section{Reviews in Colorado Archaeology}

Reviews in Colorado Archaeology (RCA) is an openaccess, refereed journal that publishes authoritative and critical syntheses, reviews, thematic studies, and methodological primers for archaeologists and historic preservation professionals working in Colorado and adjacent regions. $R C A$ also periodically publishes book-length contributions. Those "special publications" are numbered separately but otherwise follow the editorial standards and review processes applied to articlelength contributions. $R C A$ is published by PCRG and is available online at www.archaeologycolorado. org.

Publishing Model

$R C A$ uses an increasingly popular open-access publishing model (Simmons College 2017). All $R C A$ contributions are freely available to anyone with an internet connection. Readers may view, download, print, copy, or distribute $R C A$ articles or special publications without restriction. Copyright protections for $R C A$ contributions are not meant to limit access, but rather to assure the stability of the published works and to secure authors' rights to be properly cited.

$R C A$ articles are published online as they become available. Each annual volume opens on January 1 and closes on December 31. Authors are encouraged to provide supplementary materials, including datasets, shapefiles, images, or supporting analyses. After each volume closes, a PDF of the complete volume, apart from supplementary material, is available for download and paper copies can be obtained from third-party, print-on-demand vendors.

All RCA contributions, including special publications, receive double-blind reviews by at least two subject-matter experts. $R C A$ does not assess publication fees and accepts contributions of any length.

\section{Journal Scope}

Contributions to $R C A$ cover all aspects of Colorado archaeology, from Paleoindian to industrial archaeology. $R C A$ articles and special publications are intended both to summarize the current state of knowledge and to provoke new thinking and new research. $R C A$ contributions are written primarily for archaeologists and other historic preservation professionals engaged in research and cultural resources management.

$R C A$ publishes five types of articles: reviews, original research, thematic studies, methods reports, and resource reports. Each type of article performs one or more functions of an archaeological context discussed previously. Taken together, contributions to $R C A$ offer incremental and targeted revisions to the current CCPA contexts.

Review articles are authoritative topical or regional summaries that build directly on the six existing Colorado contexts by highlighting recent research. They provide a medium for timely distribution of new findings.

Original research articles tackle previously identified problems by presenting new interpretations on long-standing research questions or data gaps, or by offering new conceptual approaches to the study of Colorado archaeology. Research articles expand the scope of current work or critically examine how we study and evaluate sites.

Thematic studies are explicit context statements primarily designed to provide guidance on NRHP significance evaluations. Although they do not follow the formatting of NRHP historic contexts, they incorporate the same primary elements.

Methods reports describe new field or analysis methods or documentation standards. They 
illustrate the ways new techniques can provide unanticipated or previously unattainable results and highlight the effects our methods can have on the decisions we make about site significance and research value.

Resource reports are detailed descriptions of regionally or nationally significant archaeological sites or collections. They provide current and comprehensive discussions of keystone resources, including information on previously conducted research.

Apart from its general focus on regional archaeological context development, $R C A$ places few limitations on the scope of contributions. Articles may treat a topic broadly, drawing as necessary on the results of projects conducted outside the state's nominal borders. Articles may also be tailored narrowly, focusing on a specific period, locality, or material class. Authors are encouraged to frame their topic in a way that best suits their data and most effectively advances their argument.

\section{Online Toolkit}

$R C A$ is a core component of a new website designed to support research, cultural resources management, and public education in Colorado archaeology. Called "Online Resources for Colorado Archaeology and Historic Preservation" or ORCA, the site is an open access platform that integrates a research library, a compendium of links to online resources, and tools for online communication and collaboration.

The library primarily features documents published after 1999, though it also incorporates selected legacy documents. The list of online resources includes a wide variety of non-commercial websites maintained by universities, state and federal agencies, and nonprofit organizations that are designed for students, avocationals, and professionals. ORCA also provides links to a variety of archaeology education resources. ORCA's online forum offers the state's community of professional and avocational archaeologists a venue for asking questions, sharing ideas, or finding colleagues with similar interests. The ORCA site also provides a venue for sharing summaries of completed or ongoing projects and for distributing archaeological and archival data in digital formats.
The ORCA website was built with two primary goals in mind: to provide a platform for the creation and distribution of context documents useful for archaeological research and cultural resources management and to strengthen and expand the community of Colorado archaeologists. It will achieve those goals to the extent that professional and avocational archaeologists use the tools it provides and, moreover, contribute to their development.

Acknowledgements. Rich Wilshusen and Chris Johnston provided comments and recommendations that greatly improved this article. I have known both Rich and Chris for many years and have come to rely on their sound judgments and creative insights. To both I owe a great deal for pushing me to think creatively about archaeological problems and archaeological practice.

\section{References Cited}

Altschul, Jeffrey H.

2005 Significance in American Cultural Resource Management: Lost in the Past. In Heritage of Value, Archaeology of Renown: Reshaping Archaeological Assessment and Significance, edited by Clay Mathers, Timothy Darvill, and Barbara J. Little, pp. 192-210. University Press of Florida, Gainesville, Florida.

Briuer, Frederick L., and Clay Mathers

1997 Trends and Patterns in Cultural Resource Significance: An Historical Perspective and Annotated Bibliography. Technical Report EL-97-5. U.S. Army Corps of Engineers, Waterways Experiment Station, Vicksburg, Mississippi.

Darvill, Timothy

1995 Value Systems in Archaeology. In Managing Archaeology, edited by Malcolm A. Cooper, Antony Firth, John Carman, and David Wheatley, pp. 38-48. Routledge, London.

2005 "Sorted for Ease and Whiz"? Approaching Value and Importance in Archaeological Resource Management. In Heritage of Value, Archaeology of Renown: Reshaping Archaeological Assessment and Significance, edited by Clay Mathers, Timothy Darvill, and Barbara J. Little, pp. 21-42. University Press of Florida, Gainesville.

Doelle, William H., Pat Barker, David Cushman, Michael Heilen, Cynthia Herhahn, Christina Rieth

2016 Incorporating Archaeological Resources in Landscape-Level Planning and Management. Advances in Archaeological Practice 4(2):118-131

King, Thomas F.

2003 Places That Count: Traditional Cultural Properties in Cultural Resource Management. Altamira, Walnut Creek, California. 
Lipe, William D.

1984 Value and Meaning in Cultural Resources. In Approaches to the Archaeological Heritage, edited by Henry Cleere, pp. 1-11. Cambridge University Press, Cambridge.

2006 Archaeological Values and Resource Management. In Archaeology \& Cultural Resource Management, edited by Lynne Sebastian and William D. Lipe, pp. 41-63. School for Advanced Research, Santa Fe, New Mexico.

National Park Service

1997a Guidelines for Completing National Register of Historic Places Forms, Part A: How to Complete the National Register Registration Form. National Register Bulletin 16a. U.S. Department of the Interior, National Park Service, Washington, D.C.

1997b How to Apply the National Register Criteria for Evaluation. National Register Bulletin 15. U.S. Department of the Interior, National Park Service, Washington, D.C.

2002 Federal Historic Preservation Laws. U.S. Department of the Interior, National Park Service, National Center for Cultural Resources, Washington, D.C.

Schiffer, Michael B., and John H. House

1977 An Approach to Assessing Scientific Significance. In Conservation Archaeology: A Guide for Cultural Resource Management Studies, edited by Michael B. Schiffer and George J. Gumerman, pp. 249-257. Academic Press, New York.

Schlanger, Sarah, Richard Wilshusen, and Heidi Roberts

2015 From Mining Sites to Mining Data: Archaeology's Future. Kiva 81(1-2):80-99.
Simmons College, School of Library and Information Science

2017 Open Access Directory. Electronic resource, http://oad.simmons.edu/oadwiki/Main_Page, accessed December 20, 2017.

U.S. Forest Service

2015 Heritage Program Management Handbook. Forest Service Handbook 2309.12. Electronic document, https://www.fs.usda.gov/Internet/FSE DOCUMENTS/ fseprd517819.pdf, accessed December 20, 2017.

World Heritage Committee

2017 Operational Guidelines for the Implementation of the World Heritage Convention. WHC.17/01. United Nations Educational Scientific and Cultural Organization, Intergovernmental Committee for the Protection of the World Cultural and Natural Heritage. World Heritage Center, Paris, France.

\section{Contributor Notes}

Mark Mitchell is Research Director for Paleocultural Research Group, a nonprofit that conducts research, trains students, and educates the public on the archaeology and paleoecology of the Great Plains and Rocky Mountains. Previously, he worked for several cultural resource management firms and for the USDA Forest Service in Colorado, Wyoming, and Kansas. He earned his Ph.D. from the University of Colorado at Boulder and his M.A. from the University of Colorado at Denver.

ORCiD

https://orcid.org/0000-0003-4494-8840 